portional to yield of fiber. This latter is also shown by Nos. 2, 8, 2I and 22, where yield is fairly regular and specific gravity is irregular. This would indicate that habit and environment have much to do with the quality. of wood.

II-We can establish very well the influence of incipient decay upon the yield by comparing Nos. I 2, I 7 and I8, all of which are sound specimens, with Nos. 3, 4, 5 and 6 ; the annual ring growths compare averages about 48 or 75 per cent, showing that the voids in 2 feet wood are less than in 4 feet wood. Comparing the solid cubic feet we find it to be about Ioo in the case of 2 feet wood and 95 in 4 feet wood.

From experiments not shown here, it has been proven that large wood contains more solid wood per cord than small sizes, in the ratio of about 96 to 92 .

From these results it is apparent how important it is to the manufacturer of chemical pulp to know

TABLE I-MONTMORENCY WOOD TEST (NOVEMBER, 1912)

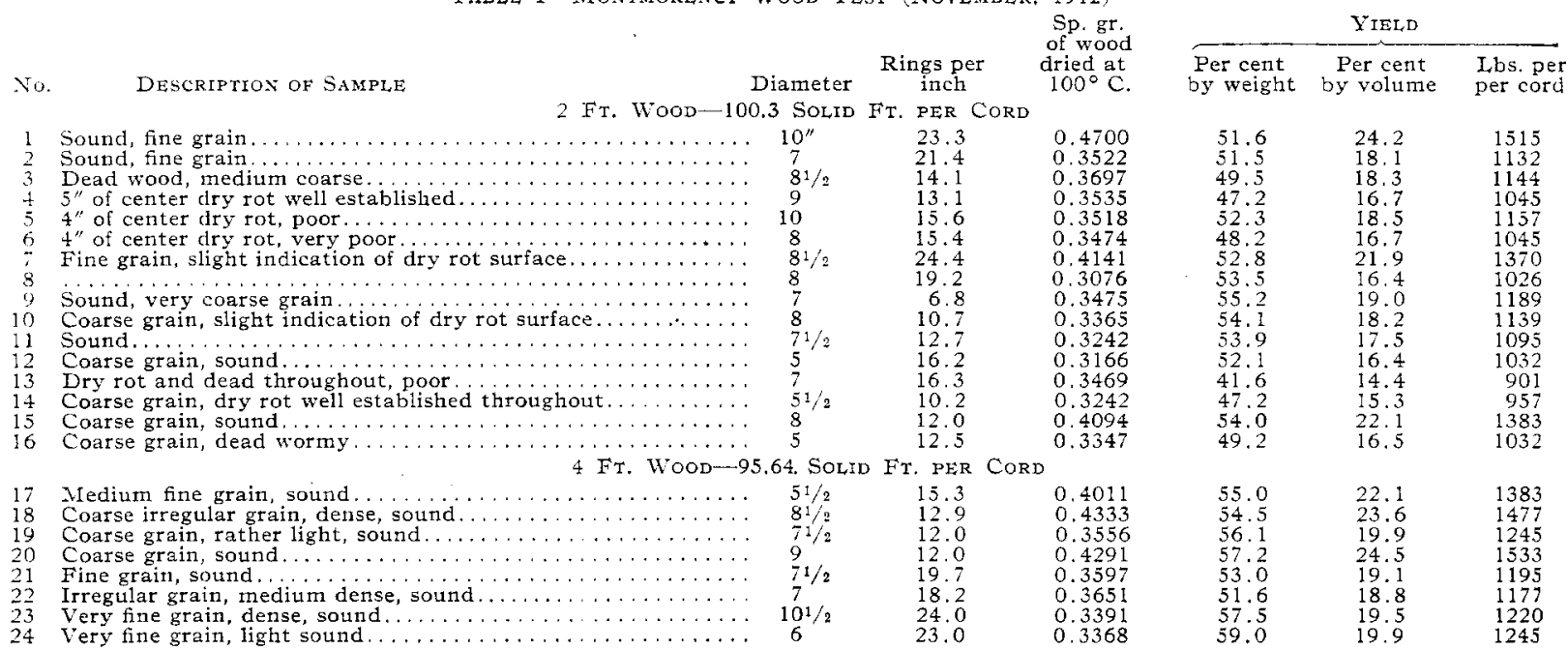

favorably and yet the specific gravities and yields of the latter are noticeably low.

III-The most important conclusion of all and the one we are perfectly safe in drawing is that there is great variation in the yield of chemical pulp and that some consideration should be given to this yield in fiber in valuing wood for pulp.

The yield per cord is found by taking the solid volume which the author has found to be about roo cu. ft. and multiplying by the specific gravity. This gives the cord weight basis from which the yield in fiber can be calculated.

The volume yield is found by multiplying the specific gravity into the percentage fiber yield. The specific gravity of wood is very quickly determined approximately by displacement in mercury instead of water.

\begin{tabular}{|c|c|c|c|c|c|c|c|}
\hline \multirow[b]{2}{*}{$\begin{array}{l}\text { Moisture } \\
\text { per cent }\end{array}$} & \multicolumn{2}{|c|}{$\begin{array}{l}\text { Weight of } \\
\text { one cord Lbs. }\end{array}$} & \multicolumn{2}{|c|}{ Area in one cord } & \multicolumn{2}{|c|}{$\begin{array}{l}\text { Volume } \\
\text { in one cord }\end{array}$} & \multirow{2}{*}{$\begin{array}{l}\text { No. of } \\
\text { sticks in } \\
\text { one cord }\end{array}$} \\
\hline & Wet & $\frac{\text { Lis. }}{\text { Dry }}$ & $\begin{array}{l}\text { Actual } \\
\text { sq. ft. } \\
2 \text { FT }\end{array}$ & $\begin{array}{l}\text { Per cent } \\
\text { total } \\
\text { Wood }\end{array}$ & $\begin{array}{l}\text { Actual } \\
\text { cu. ft. }\end{array}$ & $\begin{array}{c}\text { Per cent } \\
\text { total }\end{array}$ & \\
\hline $\begin{array}{l}40.1 \\
43.3 \\
38.4 \\
38.4 \\
48.7 \\
48.7\end{array}$ & $\begin{array}{l}3990 \\
3992 \\
3636 \\
3616 \\
4395 \\
4255\end{array}$ & $\begin{array}{l}2392 \\
2220 \\
2240 \\
2228 \\
2140 \\
2075\end{array}$ & $\begin{array}{l}49.4 \\
48.5 \\
51.65 \\
51.15\end{array}$ & $\begin{array}{l}77.2 \\
74.8 \\
80.8 \\
79.8\end{array}$ & $\begin{array}{r}98.8 \\
97.0 \\
103.3 \\
102.3\end{array}$ & $\begin{array}{l}77.2 \\
74.8 \\
80.8 \\
79.8\end{array}$ & $\begin{array}{l}178 \\
185 \\
210 \\
184\end{array}$ \\
\hline $\begin{array}{l}24.44 \\
31.00\end{array}$ & $\begin{array}{l}3014 \\
3313\end{array}$ & $\begin{array}{l}2277 \\
2286\end{array}$ & $\begin{array}{r}4 \mathrm{Fr} \\
24.22 \\
23.60\end{array}$ & $\begin{array}{l}\text { WOOD } \\
75.70 \\
73.75\end{array}$ & $\begin{array}{l}96.88 \\
94.40\end{array}$ & $\begin{array}{l}75.70 \\
73.75\end{array}$ & $\begin{array}{r}80 \\
109\end{array}$ \\
\hline
\end{tabular}

Table II shows the weights per cord of mixed spruce and balsam fir containing different percentages of moisture and the dry weight, which averages about $2200 \mathrm{lbs}$, free from moisture.

Comparing the square foot cross-section of a cord of 2 feet and 4 feet woods, we observe that the former averages about 50, or 78 per cent, while the latter what his wood will yield and for his purposes it should be valued accordingly. Progress in valuing wood in any other way than by the cord unit will be slow, because all timber having a dimension lumber value will necessarily be valued by dimension. Again, as wood finds various markets, it will be valued according to the use it is put to in the highest market and the tendency to value all wood by the unit measurement of the principal market will persist. Meanwhile conditions are rapidly changing whereby the poorer grades of wood only are finding their way to the pulp mills and the question of supply and demand are determining factors.

So far as the author knows, manufacturers of pulp have done little or nothing to promote a better standard of valuing wood for their uses and we may expect no change until they take this matter more seriously in the interest of more efficient management of their plants.

RUMFORD, MAINE

\section{DETERMINATION OF CARBON IN SOILS AND SOIL EXTRACTS}

\section{By J. W. Ames and E. W. Gaither}

Received April 6, 1914

The method of estimating total carbon in soils by oxidation with a mixture of chromic and sulfuric acids has been tested by different chemists with varying results. Warrington and Peake ${ }^{1}$ found that the chromic acid method gave lower results than those obtained by combustion in current of oxygen. Later, Cameron and Breazeale ${ }^{2}$ compared the chromic acid

\footnotetext{
1 Jour. Chem. Soc., $37(1880), 617$
}

2 Jour. Am. Chem. Soc., 26, 29. 
combustion with dry ignition in combustion furnace; the lower results obtained with chromic acid combustion as practiced by them, were no doubt due to the fact that the mixture was heated only until the sulfuric acid began to give off fumes. Hall and Miller reexamined the method and concluded that the error was due to incomplete oxidation, other substances than carbon dioxide being produced. They found that by passing the products of combustion over heated copper oxide, all the carbon could be obtained as carbon dioxide. Their method calls for the addition of concentrated sulfuric acid and heating before chromic acid is added, which may account for the differences found.

Soil investigations in progress required the determination of carbon in I per cent hydrochloric acid and 4 per cent ammonia extracts of soils. Since neither the combustion furnace nor Parr apparatus ${ }^{2}$ could be used on account of impracticability of reducing volume of solution to dry condition for combustion in boat or explosion bomb, the chromic acid combustion suggested itself as the most feasible method.

This led to a thorough test of the method for total carbon in soils, as compared with results obtained by combustion with copper oxide in furnace. The use of the Brown and Escombe double titration method for estimating carbonate in presence of sodium hydrate as suggested by $\mathrm{Amos}{ }^{3}$ and a modification of his apparatus has contributed much to the successful operation of the chromic acid combustion as practiced in this work. The apparatus as modified by the junior author is shown in cut with accompanying explanatory details. It can be assembled on a single ring stand and requires only 16 inches table space. The absorption tube permits of a much smaller volume of 4 per cent solution of sodium hydroxide for absorption of carbon dioxide, thus reducing the blank and making it practicable to titrate the entire solution instead of an aliquot.

By adopting this procedure for determination of carbon dioxide rather than that of weighing an $a b-$ sorption bulb, the long purifying train is eliminated. The only substance likely to interfere with the titration would be hydrogen sulfide which could scarcely be evolved from such a strong oxidizing solution. This method was found to be applicable for estimation of carbon dioxide evolved from either the wet or dry combustion, and was used throughout the work here reported.

The soil samples selected for this work varied considerably as to their formation and content of inorganic and organic carbon.

\begin{tabular}{|c|c|c|c|}
\hline \multirow[b]{3}{*}{ Iab. No. } & \multirow{2}{*}{\multicolumn{2}{|c|}{ DESCRIPTION OF SOLLS }} & \multirow{3}{*}{$\begin{array}{c}\text { Mineral } \\
\text { carbon } \\
\text { Marr method } \\
\text { per cent }\end{array}$} \\
\hline & & & \\
\hline & Origin & $\begin{array}{l}\text { Litmus } \\
\text { reaction }\end{array}$ & \\
\hline $\begin{array}{l}4655 \ldots \ldots \ldots \ldots \ldots \\
4754 \ldots \ldots \ldots \ldots \ldots \\
4755 \ldots \ldots \ldots \ldots \\
5577-1 \ldots \ldots \ldots \ldots \\
1416-3 \ldots \ldots \ldots \ldots\end{array}$ & $\begin{array}{l}\text { Swamp clay } \\
\text { Limestone clay } \\
\text { Limestone clay } \\
\text { Silt loam } \\
\text { Prairie }\end{array}$ & $\begin{array}{l}\text { Very acid } \\
\text { Neutral } \\
\text { Very alk. } \\
\text { Acid } \\
\text { Neutral }\end{array}$ & $\begin{array}{l}0.000 \\
0.024 \\
0.444 \\
0.000 \\
0.000\end{array}$ \\
\hline & TOTAL CARBON & & \\
\hline
\end{tabular}

The following methods were employed for estimation of total carbon in soil.

1 Jour. Chem. Soc., 89 (1906), 595.

2 Jour. Am. Chem. Soc., 26, 296-1640.

3 Jour. Agr. Sci., 1, Part 3, 322.
I-IGNition IN FURNACE WITH COPPER OXIDEFrom I to 3 grams of soil were thoroughly mixed in an agate mortar with five times its weight of copper oxide, transferred to porcelain boat and ignited in glass tube at bright red heat for 30 minutes, a current of $\mathrm{CO}_{2}$ free air passing through tube carrying products of combustion over heated copper oxide during the whole time. The gas was turned off and air allowed to pass for Io minutes. The carbon dioxide produced was absorbed in $25 \mathrm{cc}$. of 4 per cent sodium hydroxide made from sodium. When combustion was complete, the absorption solution was drawn out, the tower washed with I $50 \mathrm{cc}$. carbon dioxide-free distilled water and the solution titrated by double titration. using phenolphthalein and methyl orange.

2-COMBUSTION WITH CONCENTRATED CHROMIC AND SULFTRIC ACID MIXTURE-From I to 3 grams of soil were weighed into a $250 \mathrm{cc}$. short neck Kjeldahl nitrogen flask connected to apparatus; Io cc. chromic acid solution containing 3.3 grams, then $50 \mathrm{cc}$. of concentrated sulfuric acid were run in through separatory funne1. This mixture was boiled 30 minutes, during which time a moderate current of carbon dioxidefree air was passed into the boiling mixture, sweeping out the carbon dioxide evolved, which was absorbed and titrated as under copper oxide combustion.

COMBUSTION WITH DILUTE CHROMIC AND SLLFURIC ACID MIXTURE-The same as for concentrated chromic acid except that $50 \mathrm{cc}$. of water were added before the chromic and stilfuric acids.

3-combustion with alkaline permangaxateFrom I to 3 grams of soil were placed in $250 \mathrm{cc}$. Kjeldahl flask, Ioo cc. of a solution containing 8 grams sodium hydroxide and 5 grams potassium permanganate added; the flask connected to the apparatus and boiled for one hour; the mixture was cooled, the 4 per cent solution of hydroxide placed in absorbing tower and $50 \mathrm{cc}$. of one part sulfuric acid and two parts water run into flask through separatory funnel. After boiling $I_{5}$ minutes, the carbon dioxide evolved was determined by titration.

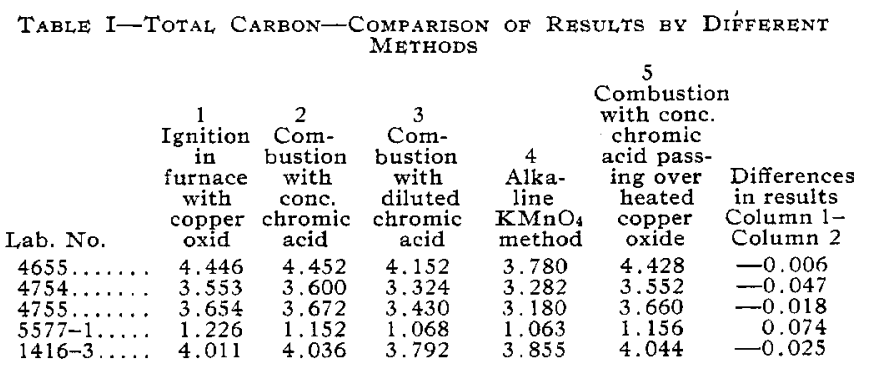

It is seen from these results, that for soils, the continued boiling with concentrated chromic acid gives results agreeing with those by the ignition method, within the limits of experimental error, while if the mixture is dilute, the results are too low, and that the results obtained with alkaline permanganate are entirely too low throughout. To determine if the oxidation with chromic acid had been carried to a complete reaction giving carbon dioxide as the final product, the gases from combustion with concentrated chromic acid mixture were passed over heated copper oxide before being 
absorbed. These results in Column 5 agree very closely with results obtained from combustion in furnace and with chromic acid mixture only (Columns I and 2).

In all cases where the digestion was made with the concentrated solution, the silicates of the soil were disintegrated and rendered gelatinous; upon dilution and filtering the digested residue, its bulk was found to be greatly increased. By rubbing in beaker with glass rod, very little grit was found to remain. On reigniting three or four of the residues in the furnace with copper oxide, no carbon dioxide was recovered. This seems to be conclusive proof that the concentrated chromic and sulfuric acid treatment ${ }^{1}$ completely decomposes organic and inorganic carbon present in soils and overcomes the objection raised by Cameron and Breazeale, and $\mathrm{Hall}$ and Miller in their articles previously cited.

CARBON IN 4 PER CENT AMMONIUM HYDROXIDE SOIL EXTRACT

To determine whether or not moderate dilution prevented the complete oxidation of humus materials by this method, three duplicate $50 \mathrm{cc}$. portions of the Grandeau humus extract, equivalent to I gram of soil, were pipetted off; two sets were evaporated to dryness on steam bath, and transferred to the digestion flasks with three successive $5 \mathrm{cc}$. portions of 4 per cent ammonium hydroxide and I $5 \mathrm{cc}$. of water. One of these sets was placed in water bath heated to $65^{\circ} \mathrm{C}$., and distilled to dryness under reduced pressure, and carbon determined on the dry residue. Carbon was determined on the other two sets without concentration.

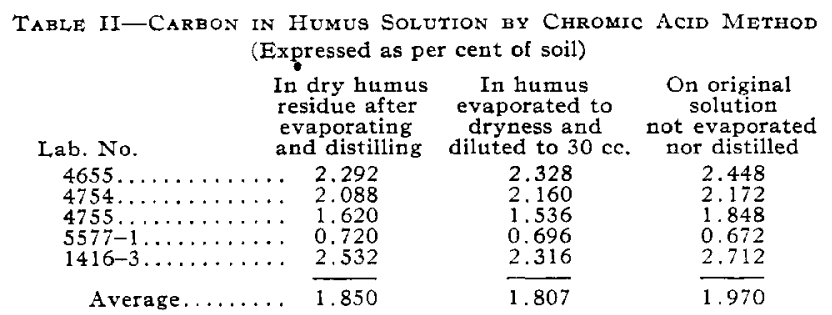

The results in Columns $\mathrm{I}$ and 2 are within the limits of experimental error and show that $30 \mathrm{cc}$. dilution does not prevent the oxidation of humus substances. The difference between the averages of Columns I and 2 , and Column 3 can be accounted for by the loss of volatile and easily oxidizable carbonaceous matter through evaporation on the steam bath. It is evident that moderate dilution does not prevent the oxidation of humus by chromic acid after it has been extracted from the soil by 4 per cent ammonium hydroxide. If all of the $\mathrm{HCl}$ is not washed from the soil before extracting with 4 per cent ammonium hydroxide, a trace of $\mathrm{Cl}$ may come over and be absorbed. This may be corrected by the addition of $1 / 2 \mathrm{cc}$. IO per cent sodium thiosulfate or by introduction of a U-tube containing silver sulfate between the digestion flask and absorption tower.

1 Adding the $\mathrm{CrO}_{2}$ before adding $\mathrm{H}_{2} \mathrm{SO}_{4}$ gives an oxidizing solution before the organic matter is charred by $\mathrm{H}_{2} \mathrm{SO}_{4}$.
CARBON IN I PER CENT HYDROCHLORIC ACID SOIL EXTRACT

At first this determination presented some difficulties. All of the chlorine and chromium chloride were not condensed in the reflux condenser, but a portion was carried over and absorbed with the $\mathrm{CO}_{2}$. This destroyed the indicators. This defect was overcome by the addition of $4 \mathrm{cc}$. of a ro per cent solution of sodium thiosulfate just before titrating. This gave a clear, sharp end point with both indicators, and no further trouble was experienced in obtaining good duplicates.

The volume of hydrochloric acid extract used was concentrated to about $30 \mathrm{cc}$. by distilling under reduced pressure before adding the chromic and sulfuric acids.

In order to test the accuracy of the methods, a set of soils, 5 grams each, were extracted with I per cent $\mathrm{HCl}$, then with 4 per cent ammonium hydroxide according to official method of the A. O. A. C., Bulletin I07, revised, Bureau of Chem., C. S. D. A.

Instead of using Gooch crucibles with asbestos mat, an alundum crucible was used, eliminating the asbestos. The I per cent hydrochloric acid extract and washings were made to a volume of $500 \mathrm{cc}$. Nine-tenths of the 4 per cent ammonium hydroxide solution was siphoned off, disturbing the settled soil as little as possible, leaving the residue from 5 grams of soil and one-tenth of the 4 per cent ammonium hydroxide extract. This was transferred to beakers, evaporated, dried, ground in an agate mortar and weighed. One-fifth of this was weighed into the digestion flasks, carbon determined, and results calculated to per cent of carbon on basis of original soil, allowing for the carbon in the 4 per cent ammonium hydroxide. Carbon was determined on the $\mathrm{I}$ per cent $\mathrm{HCl}$ and 4 per cent $\mathrm{NH}_{4} \mathrm{OH}$ extracts, and the mineral carbon was determined by the Marr method. ${ }^{1}$ The sum of these fractions should equal the total carbon found in the soil.

TABLE III-Comparison OF Sum of Fractional Determination of

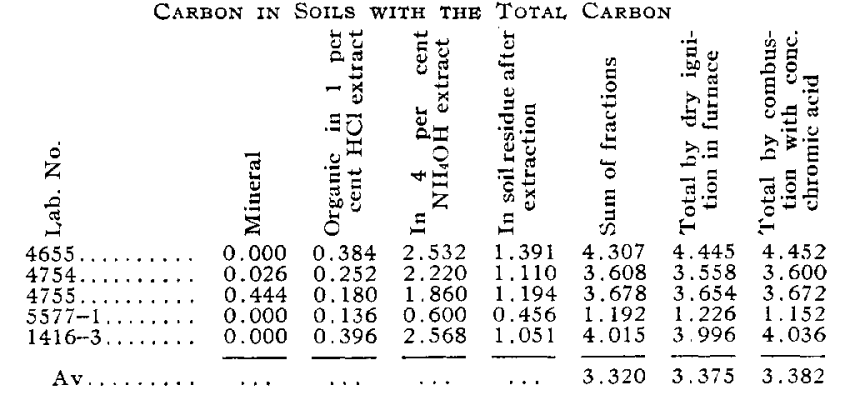

It is seen from these results that the average differences between the total carbon determined direct, and the sum of the fractions are well within the limits of experimental error, and that the method as applied to soil extracts is reliable and accurate. In all the work here reported, every fifth determination was a blank made under exactly the same conditions as the determinations so that the necessary correction could be made.

OPERATION OF APPARATUS

If it is desired to free the apparatus from $\mathrm{CO}_{2}$ 1 Jour. Agr. Sci., 3, Part 2, 155. 
before starting a determination, the arrangement shown at $Q$ may be inserted, glass "T" $k k$ at $K$ and glass " $T$ " $l l$ at $L$, connected by tube $O$. By closing $N$ and $R$ and opening $P$, the $\mathrm{CO}_{2}$ may be removed from $D$, or by connecting $S$ with a tower similar to

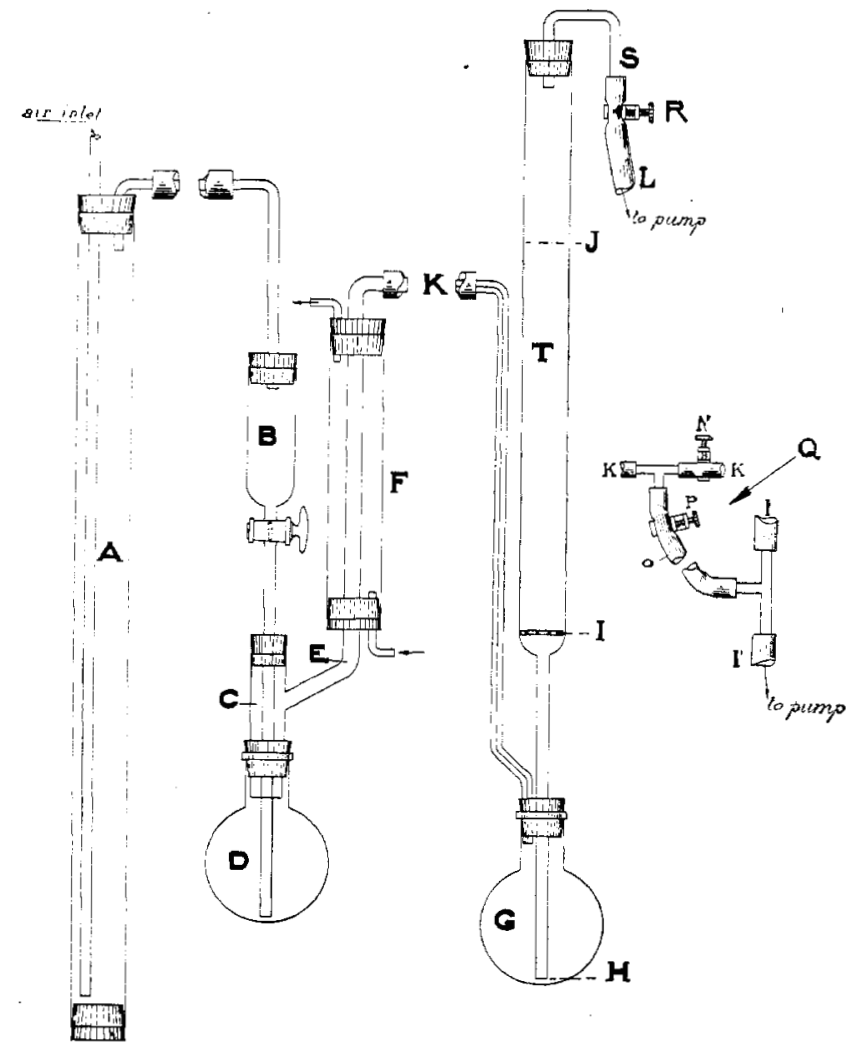

$A$ and leaving $N$ and $P$ open, closing $R$, the whole apparatus may be freed from $\mathrm{CO}_{2}$. This is usually unnecessary since the blank takes care of the $\mathrm{CO}_{2}$ that is in the apparatus.

The sample is placed in $D$ which is connected to $C$. The absorbing liquid is placed in $G$ and this connected to tower $T$. The stopcock in $B$ is closed and digesting liquid placed in $B$ which is then connected to $A$. Water is started through condenser $F$ and the suction started, $R$ is slowly opened until the liquid in $G$ is drawn into $T$ and a moderate flow of air started. The stopcock in $B$ is opened and the digesting liquid run into $D$, using ordinary care. When air begins to flow from $A$, the heat is applied to $D$ and the process continued to completion. When this point is reached, remove flame, close $R$, disconnect $B$, then $G$, and remove stopper from tower $T$. Receive content of $T$ in $G$ and wash out $T$ with roo cc. of $\mathrm{CO}_{2}$-free water, using successive $25 \mathrm{cc}$. portions and titrate content of $G$.

The tower $A$ and apparatus $T-G$ may be used for the determination of carbon by ignition in a furnace, without the use of the customary purifying train.

This form of apparatus is less expensive, more easily operated, and just as efficient as the one shown in ThIS JOURNaL, 4, 6I2.

\section{CONCIUSIONS}

If boiled for 30 minutes, a mixture of 3.3 grams of chromic acid in Io cc. of water to $50 \mathrm{cc}$. of sulfuric acid (sp. gr. r.84) will oxidize all of the organic carbon and liberate all carbon dioxide chemically or mechanically held in soils, provided the soil is ground to pass 60 mesh sieve and from I to 3 grams of soil used for each $60 \mathrm{cc}$. of mixture.

If the mixture is diluted with $50 \mathrm{cc}$. of water, the results obtained are too low.

The alkaline permanganate method gives too low results.

The Brown and Escombe titration method of determining carbon dioxide, and the modified Amos absorption tower for same, are applicable to either wet or dry combustion forms of apparatus, and can be relied upon to give rapid and accurate results with considerable economy of time and space.

Carbon may be accurately determined in I per cent hydrochloric acid extracts and 4 per cent ammonium hydroxide humus solutions without concentrating below $50 \mathrm{cc}$. by using the above chromic and sulfuric acid mixture.

The apparatus described is applicable to the determination of carbon dioxide in any form, and a number of other gas determinations, depending on absorption in acid or alkalies, oxidation or reduction processes.

By using the apparatus shown in the cut, and following the method as outlined, one analyst can run six determinations at one time, and complete a set an hour when doing routine work, making it possible to run forty-eight total carbons in an eight-hour day.

\author{
Department of Chemistry \\ OHIO AGRICULTURAL EXPERIMENT STATION \\ WOOSTER
}

\section{THE MELTING AND SOLIDIFYING POINTS OF MIX- TURES OF FATTY ACIDS AND THE USE OF THESE POINTS TO DETERMINE THE COMPOSITION OF SUCH MIXTURES}

By E. Twitchel

Received March 25, 1914

The tables of melting points of mixtures of lauric, myristic, palmitic and stearic acids by Heintz ${ }^{1}$ show certain regularities which Heintz himself noted, and which are referred to by Ostwald in his "Lehrbuch der Allgemeinen Chemie," 2 d Ed., Vol. I, p. IOI 7, where he observes that it matters little which of these fatty acids of a lower melting point is added, in a certain proportion up to 40 per cent, to one of a higher, the lowering of the melting point of the latter is almost the same; also any of the fatty acids of higher melting point may be added to one of a lower (in definite proportion up to I 5 or 20 per cent) and will cause the same depression. In other words, any of the fatty acids examined, when added in a certain proportion up to 20 per cent to any other, will cause a lowering of the melting point of the solvent acid depending on the amount of the acid added but independent of its kind.

This fact he explains by the law of equal depression of the freezing point for equal molecular proportions. This explanation assumes that the different fatty acids considered have the same molecular weights, which is, of course, not true, but the molecular weight of these fatty acids, and in fact of the fatty acids found in most

1 Poggendorff's Annalen, 92, p. 588. 